\title{
Impermeability Durability of SCC Reinforced with Fibrillated Polypropylene Fiber
}

\author{
X.B. $\mathrm{He}^{*}, 1, \mathrm{Y} . \mathrm{Li}^{1}$ and Q. Shen ${ }^{2}$ \\ ${ }^{I}$ State Key Laboratory Breeding Base of Mountain Bridge and Tunnel Engineering, Chongqing Jiaotong University, \\ Chongqing, 400074, P.R. China \\ ${ }^{2}$ Research Institute of Highway Ministry of Transport, Beijing Xinqiao Technology CO., LTD, Beijing, 100001, P. R. \\ China
}

\begin{abstract}
The paper studied the influences of the volume content and slenderness ratio of fibrillated polypropylene fiber on the impermeability durability of self-consolidating concrete (SCC) reinforced with the fibrillated polypropylene fiber, and proposed to use the modified relative permeability coefficient method to evaluate the water-resistant properties of SCC reinforced with the fiber. Also, the influence mechanism of the fiber on the permeability of the concrete has been analyzed according to the mercury injection test, scanning electronic microscope (SEM) observation and the basic principles of fracture mechanics. Results showed that: 1) the total porosity of SCC gradually increased with the increase in the fiber content; 2) the harmful porosity of SCC decreased firstly and then increased with the increase in the fiber content, while the harmful porosity increased with the increase in the fiber length; 3 ) when the reference mix proportion of SCC was kept constant, the fiber volume content was not more than $0.10 \%$, and the appropriate fiber length ranged from 12 to $15 \mathrm{~mm}$; 4 ) when the volume content is no more than $0.15 \%$, the hardened SCC reinforced with fibrillated polypropylene fiber possessed good water impermeability gradation $(>\mathrm{P} 12)$; the splitting strength and flexural tensile strength of the hardened SCC reinforced with fibrillated polypropylene fiber increased with the addition of the fiber content; the relative water penetration coefficient of the hardened SCC reinforced with fibrillated polypropylene fiber decreased with the addition of the fiber content firstly and then increased; the Coulomb value first increased smoothly (the maximum Coulomb value is less than 2000C, and low according to JTJ/T 193-2009 and ASTM C 1202), and then increased sharply.
\end{abstract}

Keywords: Self-consolidating concrete, fibrillated polypropylene fiber, porosity, permeability, SCC.

\section{INTRODUCTION}

Self-consolidating concrete (SCC) reinforced with fiber is a kind of environmental friendly and high performance fiber reinforced concrete [1-3] which relies on its own gravity only to fill moulds and get compacted without vibration. Shah indicated in "Self-consolidating concrete: Now and Future" that the concrete has changed the construction mode of concrete structure in the whole world and has become the frontier of the development of concrete technology and science [4].

According to the quantitative relationship between the elastic modulus of the cement-based materials and fiber, fiber can usually be divided into rigid fiber (whose elastic modulus is one or higher than the cement-based materials in the order of magnitude) and flexible fiber (whose elastic modulus is one or more lower than the cement-based materials in the order of magnitude). Polypropylene fiber is one of the most widely applied flexible fibers in the modification of cement-based materials, which can be

*Address correspondence to this author at State Key Laboratory Breeding Base of Mountain Bridge and Tunnel Engineering, Chongqing Jiaotong University, Chongqing, 400074, P.R. China; Tel:86-23-62652369;

E-mail: david.hxb@gmail.com divided into two types: monofilament fiber and the fibrillated polypropylene fiber. Such fibers are usually used to improve the early-age shrinkage and crack resistance of cement-based materials. Related researches indicate that SCC reinforced with polypropylene monofilament fiber possesses excellent workability [3-6]; polypropylene monofilament fiber can markedly improve the performance of early-age shrinkage and crack resistance of SCC [7-8] and increase the tensile strength (including flexural-tensile strength and splitting strength) [5, 9-10], fracture toughness [11-12] and impact resistance [13], as well as the high/low temperature performance and water impermeability of the concrete [3, 14-16], however, the chloride ion permeability of the concrete increases to a certain degree [3, 17]. Fibrillated polypropylene fiber shown in Fig. (1) is composed of many cross-linked monofilament fibers through the processes of networking, short cutting and other measures. In the concrete, the fiber forms an interconnected threedimensional monofilament fiber net anchored by the concrete at ends. As a result, the concrete becomes stronger against deformation, cracking, impact and fatigue. Thus, it is a kind of highly effective material for the modification of cement-based materials $[18,19]$. There exist few related researches on the impermeability durability of SCC 
reinforced with fibrillated polypropylene fiber. The preliminary research conducted by the author found a different change law [20] regarding water permeability and chloride ion permeability of the SCC reinforced with fibrillated polypropylene fiber in length of $12 \mathrm{~mm}$. In order to reveal the intrinsic causes of the different law, this paper probed into the permeability durability of the SCC reinforced with fibrillated polypropylene fiber in different fiber slenderness ratios.

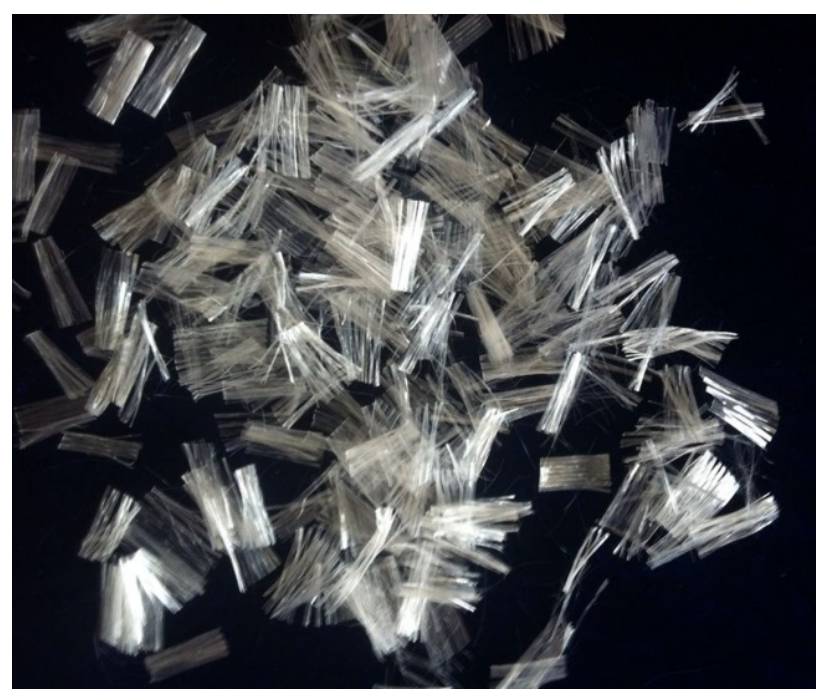

Fig. (1). Fibrillated polypropylene fiber.

Therefore, based on the research of the workability and strength characteristics of the SCC reinforced with fibrillated polypropylene fiber, the impermeability durability (including water permeability and chloride ion permeability) of the SCC reinforced with fibrillated polypropylene fiber in different lengths and volume contents has been systematically studied in this paper, and the measuring of the porous structure, SEM microstructure of the SCC and fracture mechanics method have been combined to analyze the law of the impermeability properties.

\section{EXPERIMENT}

\subsection{Raw Materials}

Ordinary Portland cement (shown in Table 1) and fly-ash (shown in Table 2) are used as binding materials; limestone with diameter of $5 \sim 20 \mathrm{~mm}$ and river sand with fineness modulus of 2.71 (shown in Table 3) [3,8]are used as aggregates; the fibers used are $12 \mathrm{~mm}, 15 \mathrm{~mm}$ and $19 \mathrm{~mm}$ long fibrillated polypropylene fibers (shown in Table 4) (it should be stated that the $19 \mathrm{~mm}$ long fiber is a mature commercial product in the market, while $12 \mathrm{~mm}$ and $15 \mathrm{~mm}$ long ones are the customized products. And when the fiber length is less than $12 \mathrm{~mm}$, the fiber is difficult to scatter into network); poly carboxylic water reducer with $27 \%$ solid content $[3,8,12,13]$ is used as super plasticizer.

\subsection{Mix Design}

The reference mix proportion of SCC is shown in Table 5 (unit: $\mathrm{kg} / \mathrm{m}^{3}$ ) $[3,8,12,13]$. The mix proportion of SCC reinforced with fibrillated polypropylene fiber was determined through the processes of trial mix and adjustment

Table 1. Technical parameters of ordinary portland cement.

\begin{tabular}{|c|c|c|c|c|c|}
\hline \multirow{2}{*}{ Sieve residue ratio / \% } & \multicolumn{2}{|c|}{ Setting time / (h:min) } & \multicolumn{2}{c|}{ 3 d strength/MPa } & \multirow{2}{*}{ Soundness } \\
\cline { 2 - 6 } & Initial & Final & Compression & 3.7 & Qualified \\
\hline \hline 3.6 & $2: 51$ & $4: 15$ & 19.3 & & Flexural \\
\hline
\end{tabular}

Table 2. Technical parameters of fly-ash.

\begin{tabular}{|c|c|c|c|c|}
\hline Sieve residue ratio / \% & Apparent density $/\left({\left.\mathrm{g} \cdot \mathbf{c m}^{-\mathbf{3}}\right)}\right.$ & Water absorption / \% & Loss ratio on ignition / \% & Water demand ratio/ \% \\
\hline \hline 4.8 & 2.48 & 0.3 & 3.2 & 93.8 \\
\hline
\end{tabular}

Table 3. Technical parameters of aggregates.

\begin{tabular}{|c|c|c|c|c|c|}
\hline Type & $\begin{array}{l}\text { Apparent density/ } \\
\left(\mathrm{g} \cdot \mathrm{cm}^{-3}\right)\end{array}$ & Water absorption/ \% & Crushing index / \% & $\begin{array}{c}\text { Flat and elongated } \\
\text { particles content } / \%\end{array}$ & Clay content / \% \\
\hline Fine aggregate & 2.67 & 2.08 & 1 & l & 0.8 \\
\hline Coarse aggregate & 2.78 & 0.13 & 12.7 & 11.3 & 0.5 \\
\hline
\end{tabular}

Table 4. Technical parameters of fibrillated polypropylene fiber.

\begin{tabular}{|c|c|c|c|c|c|}
\hline Diameter/ $\boldsymbol{\mu m}$ & Density/ $\left(\mathbf{g} \cdot \mathbf{c m}^{-3}\right)$ & $\begin{array}{c}\text { Elastic modulus/ } \\
\mathbf{M P a}\end{array}$ & $\begin{array}{c}\text { Tensile strength/ } \\
\mathbf{M P a}\end{array}$ & $\begin{array}{c}\text { Fraction elongation/ } \\
\mathbf{\%}\end{array}$ & Melting point/ ${ }^{\circ} \mathrm{C}$ \\
\hline \hline 54 & 0.91 & 3775 & 612 & 19 & 161 \\
\hline
\end{tabular}


according to the Technical Specification for Application of Fiber Reinforced Concrete of China (JGJT 221-2010) [21] until it meets the requirements of workability, strength and durability.

\subsection{Test Methods}

1) Workability of Fresh SCC Reinforced with Fibrillated Polypropylene Fiber

The binding materials (including cement and fly ash) and aggregates were dry mixed for 1 minute. Then the fibrillated polypropylene fiber was added and mixed for 2 minutes. Next, the solution containing poly carboxylic water reducer and $80 \%$ of water amount determined in the mix proportion was added and mixed for 1.5 minutes. Finally, the remaining water was added and stirred for 1 minute. In the end, as soon as the mixing stopped, the slump flow (SF) and the filling height difference $(\Delta \mathrm{h})$ by U-box were tested. When the SF is no less than $550 \mathrm{~mm}$ and the $\Delta \mathrm{h}$ is no more than $30 \mathrm{~mm}$, the workability of the fresh SCC reinforced with fibrillated polypropylene fiber is in accordance with the requirements of workability. However, if any one of SF and $\Delta \mathrm{h}$ do not meet the requirements, the reference mix proportion should be adjusted until it meets the requirements $[3,8,12,13]$.

\section{2) Strength Test for Hardened SCC with Reinforced Fibrillated Polypropylene Fiber}

For the SCC meeting requirements of workability, a $28-$ day strength test was carried out regarding the aspects of compressive strength, splitting strength and flexural-tensile strength [22] to determine the ranges of the fiber content and fiber length.
3) Impermeability of Hardened SCC Reinforced with Fibrillated Polypropylene Fiber

For the SCC reinforced with fibrillated polypropylene fiber which possesses qualified workability and strength, water penetration resistance test and chloride ion penetration test [23-25] were conducted according to Test Methods of Cement and Concrete for Highway Engineering of China (JTG E30-2005) [22]. In water penetration resistance test, each group of the hardened SCC contained 6 test samples. In the chloride ion penetration test, each group owned 3 test samples. The test for water impermeability of the SCC was performed to determine the impermeability gradation 22 of samples after a 28-day curing period. The test for water penetration depth of the SCC was used to quantitatively evaluate relative water penetration coefficient after a 28 -day curing period together with the mercury injection test. The chloride penetration test was used to measure the respective charge passed after a 28-day and a 56-day curing period.

\section{RESULTS AND ANALYSIS}

\subsection{Effect of Fibrillated Polypropylene Fibers on the Workability of fresh SCC}

With the addition of fibrillated polypropylene fiber, the workability of the fresh SCC is shown in Table 6 . When the length of the fiber was kept constant $(12 \mathrm{~mm})$, the workability of the fresh SCC decreased with the increase in the fiber volume content, and the maximum fiber volume content was $0.10 \%$ based on its workability. When the fiber volume content was kept constant $(0.10 \%)$, its workability loss was not so significant at first with the increase in fiber length (the negative effect caused by the increase of fiber length approximately offsets the effect resulted from the

Table 5. Reference mix proportion of self-consolidating concrete.

\begin{tabular}{|c|c|c|c|c|c|}
\hline Water & Cement & Fly ash & Coarse aggregate & Fine aggregate & Polycarboxylate \\
\hline \hline 165 & 385 & 165 & 834 & 834 & 5.5 \\
\hline
\end{tabular}

Table 6. Workability of fresh SCC with fibrillated polypropylene fiber.

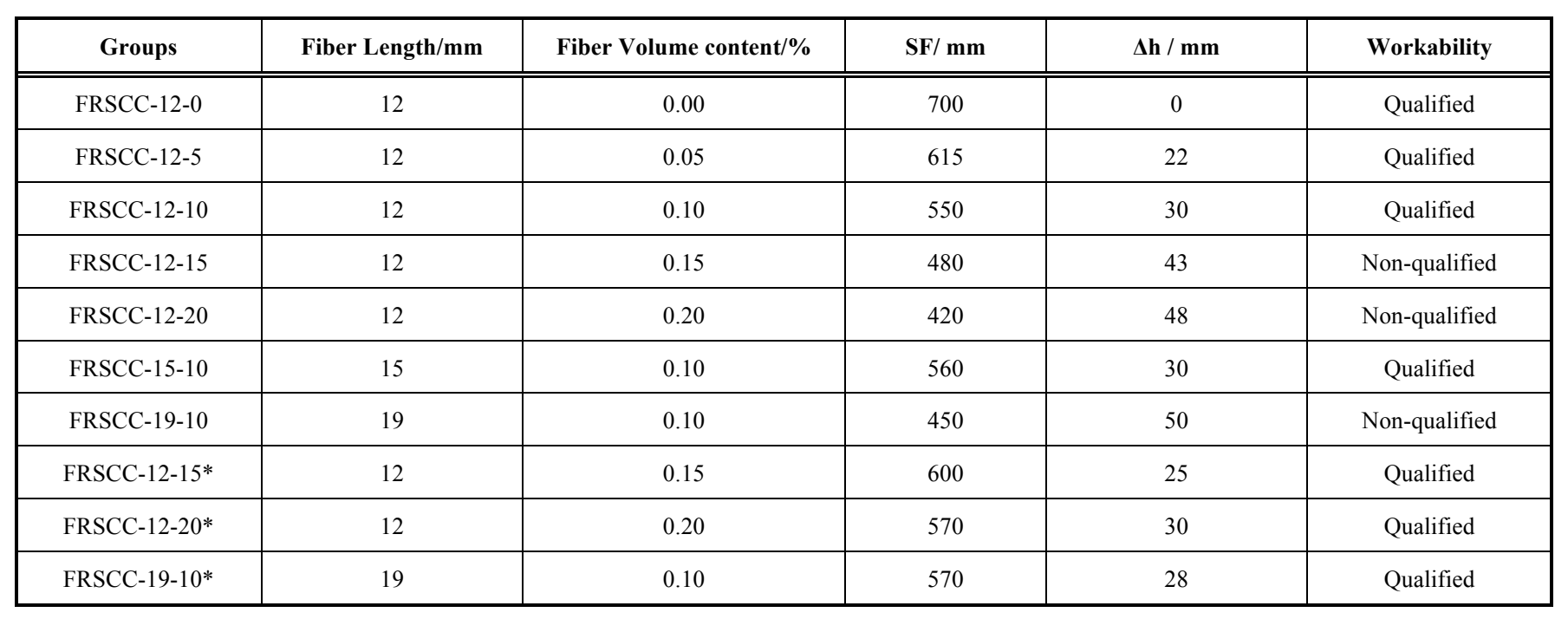


decrease of the amount of fiber), but when the fiber length was up to $19 \mathrm{~mm}$, its workability dramatically declined. Concerning the variation gradient problem of volume content, there are already a lot of reference literatures for it. During the trial mix, the author found that when the fibrillated polypropylene fiber content was added into the concrete increasing it by $0.13 \%$, the workability of the fresh SCC could not meet the requirements. If the volume content continued to increase, the workability needed to be improved also, thus a volume variation gradient of $0.05 \%$ was suitable for the increase of volume content.

The workability of the groups of FRSCC-12-15, FRSCC12-20 and FRSCC-19-10 cannot meet the requirements. In the paper, the mix proportions of FRSCC-12-15, FRSCC-1220 and FRSCC-19-10 were adjusted by increasing the binding material and poly carboxylic water reducer until they met the requirements of workability (during the adjustment process, the water-binder ratio remained unchanged basically). FRSCC-12-15* was obtained by the adjustment of the mix proportion of FRSCC-12-15, with binding material and poly carboxylic water reducer being added to $570 \mathrm{~kg} / \mathrm{m} 3$ and $1.25 \%$ respectively; while the binding material and poly carboxylic water reducer of FRSCC-12$20 *$ wererespectively raised to $590 \mathrm{~kg} / \mathrm{m} 3$ and $1.5 \%$ and that of FRSCC-19-10* were respectively increased to $590 \mathrm{~kg} / \mathrm{m} 3$ and $1.25 \% .7$ groups of fresh SCC reinforced with fibrillated polypropylene fiber were obtained (shown in Table 6).

During the preparation of the mixture, it was found that when the fiber volume content reached $0.15 \%$, the dispersibility of fiber underperformed and the clustering phenomenon of fiber was severe, and it was also noted that the workability loss of the mixture was significant. In contrast to FRSCC-12-15* group, the fiber volume content of FRSCC-12-20* group increased from $0.15 \%$ to $0.2 \%$, but its workability was not so favorable, while the segregation and bleeding phenomenon of mixture occurred. The same clustering phenomenon of fiber also appeared in FRSCC-19$10^{*}$ group. Therefore, the volume content of fibrillated polypropylene fiber should not be more than $0.15 \%$ and its length should not be more than $15 \mathrm{~mm}$.

\subsection{Strength of Hardened SCC Reinforced with Fibrillated Polypropylene Fiber}

It is displayed in Fig. (2) that when the fiber length is constant $(12 \mathrm{~mm})$, the tensile strength (including splittingtensile and flexural-tensile strength) of hardened SCC reinforced with fibrillated polypropylene fiber firstly increases with the increase of fiber volume content and then decreases. When the volume content is up to $0.15 \%$, tensile strength reaches its maximum. Compared with the reference hardened SCC, the splitting-tensile and flexural-tensile strengths of hardened SCC reinforced with fibrillated polypropylene fiber are respectively increased by $29 \%$ and $32 \%$. However, when the fiber volume content increases from $0.10 \%$ to $0.15 \%$, the increment of the strength is not so remarkable. It is shown in Fig. (3) that when the fiber volume content is constant $(0.10 \%)$, the splitting-tensile and flexural-tensile strengths of hardened SCC reinforced with fibrillated polypropylene fiber increase slightly with the increase in fiber length, but the increment is not so obvious (maximum growth is only $6 \%$ ).

\subsection{Impermeability of SCC Reinforced with Fibrillated Polypropylene Fiber}

\subsubsection{Impermeability Gradation}

Progressive hydraulic pressure method is employed in Standard for Quality Control of Concrete (GB 50164-2011) 23and Evaluation Standard of Inspection of Concrete Durability (JGJ/T 193-2009) 24of China. According to this method, impermeability gradation is divided into "P4, P6, $\mathrm{P} 8, \mathrm{P} 10, \mathrm{P} 12$ and $>\mathrm{P} 12$ ".

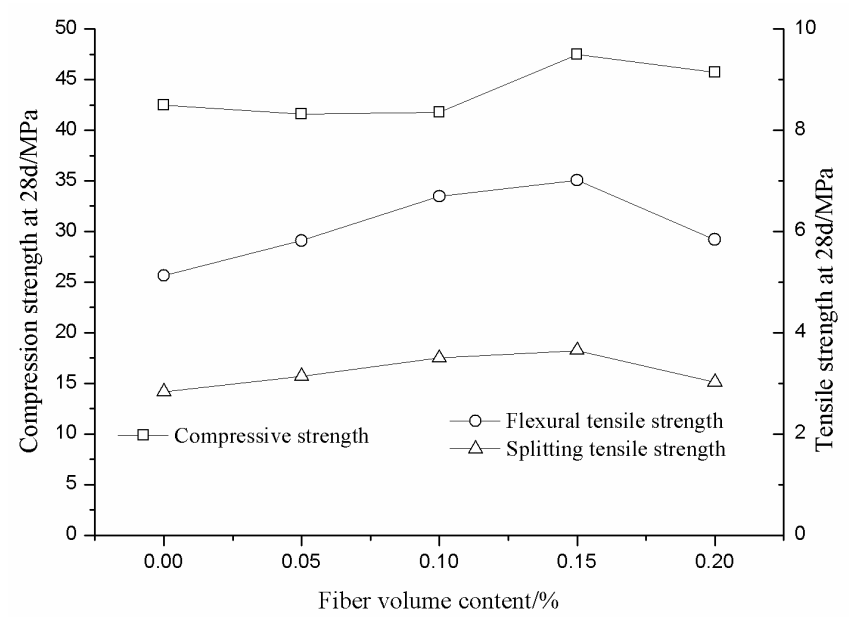

Fig. (2). Plot of strength of hardened SCC with fibrillated polypropylene fiber $v s$. fiber volume content.

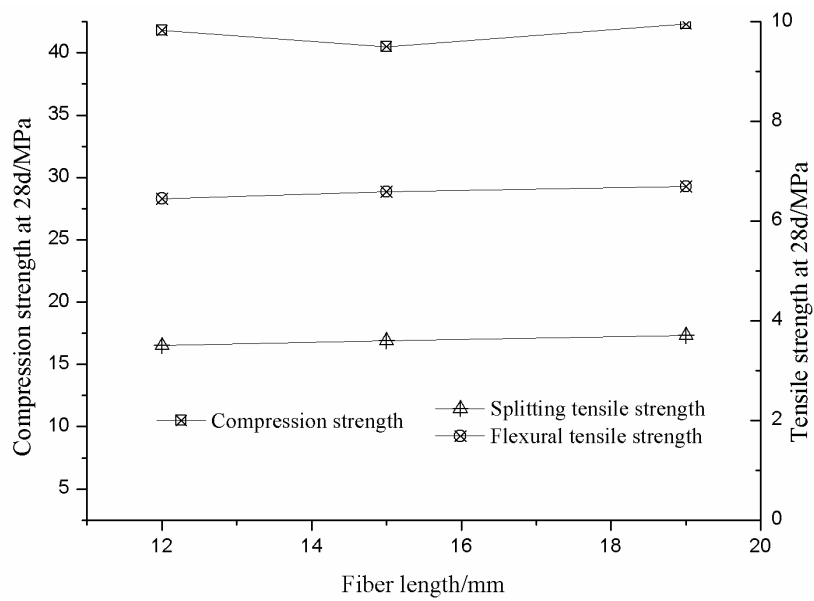

Fig. (3). Plot of strength of hardened SCC with fibrillated polypropylene fiber $v s$. fiber length.

When the hydraulic pressure increased to $3.6 \mathrm{MPa}$, water seepage did not appear on the surface of the test samples in FRSCC-12-0, FRSCC-12-5, FRSCC-12-10, FRSCC-12-15* and FRSCC-15-10 groups and the impermeability gradation was greater than P12.

4 hours after the test samples in FRSCC-12-20* group were set up in the water impermeability instrument, water seepage appeared on the surface of 3 test samples, and water pressure was $0.16 \mathrm{MPa}$, so its impermeability gradation was less than P4. While in FRSCC-19-10* group, when the water pressure reached $0.4 \mathrm{MPa}$, water seepage appeared on the surface of 4 test samples and its impermeability gradation was less than P4. 
Therefore, when the fiber length is not more than $15 \mathrm{~mm}$ and fiber volume content is not more than $0.15 \%$, the impermeability gradation of SCC reinforced with fibrillated polypropylene fiber is larger than $\mathrm{P} 12$, and the impermeability test method of cement concrete cannot be applied in the quantitative evaluation of the influence of fibers on the impermeability properties of the hardened SCC.

\subsubsection{Modified Relative Water Penetration Coefficient}

When the experiment groups whose impermeability gradation was larger than P12 was pressurized to $3.6 \mathrm{MPa}$, the pressure was kept constant for 24 hours, and then the test was stopped and the test samples were splitted. Next, the penetration depth was measured at ten equal division lines of each sample. Finally, the average penetration depth $(\bar{h})$ was calculated for each group. The formula for the relative water penetration coefficient is as follows:

$S_{k}=\alpha \frac{\bar{h}^{2}}{2 T H}$

Where, $\alpha$ is the average porosity of test samples whose diameter is larger than $100 \mathrm{~nm} ; \bar{h}$ is the average penetration depth (cm); $T$ is the constant time (hour); $H$ is water head height $(\mathrm{cm})$ converted from the water pressure; $S_{k}$ is the relative water penetration coefficient $(\mathrm{cm} / \mathrm{h})$.

The water absorption rate of concrete is employed by the relative water penetration coefficient formula in Test Code for Highway Engineering and Cement Concrete (JTE E302005) [22] and Test Code for hydraulic concrete (SL3522006) [25] of China to modify the relative water penetration coefficient, but it is difficult to assess in the actual operation, for the concrete contains hydro soluble $\mathrm{Ca}(\mathrm{OH}) 2$. According to the International Union of Pure and Applied Chemistry (IUPAC), pores whose diameter is above $50 \mathrm{~nm}$ belong to big pores, and pores whose diameter is above $10 \mathrm{~nm}$ can exert influence on the permeability properties. Based on the distribution characteristics of pores in concrete, I O.M. Butt and Academician Zhongwei $\mathrm{Wu}$ claimed that the pores influencing permeability are with the diameter of more than $100 \mathrm{~nm}$. Thus, the pores whose diameter was above $100 \mathrm{~nm}$ diameter were taken for this study to modify the relative water penetration coefficient.

According to the results of the mercury injection test, the total porosity and the harmful porosity of pores whose diameter was above 100 are shown in Figs. (4-6) respectively displaying the relationship between the modified relative water penetration coefficient of hardened SCC reinforced with fibrillated polypropylene fiber in 28day curing period and fiber volume content, and the relationship between the modified relative water penetration coefficient of hardened SCC with fibrillated polypropylene fiber after 28-day curing period and fiber length.

It can be concluded from Figs. (4-6) that with the increase in fiber volume content, the total porosity keeps on increasing and the harmful porosity firstly decreases and then increases, of which the critical volume content is $0.10 \%$. The modified relative water penetration coefficient can quantitatively reflect the water permeability of SCC. When the fiber length is constant (12 $\mathrm{mm}$, for example), with the increase in fiber volume content, the modified relative water penetration coefficient firstly decreases and then increases; and when the fiber volume content reaches $0.10 \%$, the modified relative water penetration coefficient reaches its minimum value. When the fiber volume content is constant $(0.10 \%)$, the modified relative water penetration coefficient firstly decreases slowly and then sharply increases with the increase of fiber length, and generally, when the fiber length is no more than $15 \mathrm{~mm}$, the water permeability is relatively low.

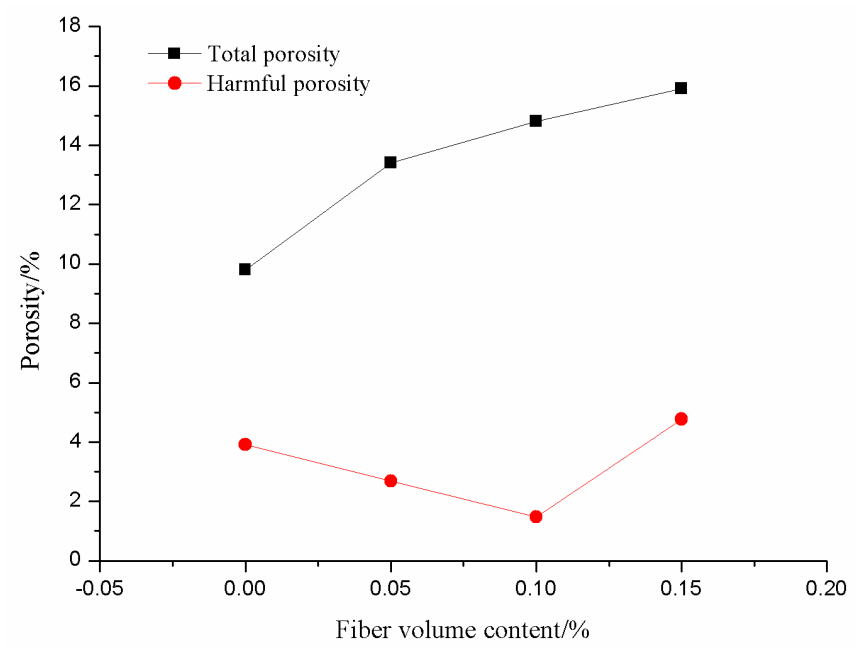

Fig. (4). Plot of porosity of hardened SCC with fibrillated polypropylene fiber $v s$. fiber volume content.

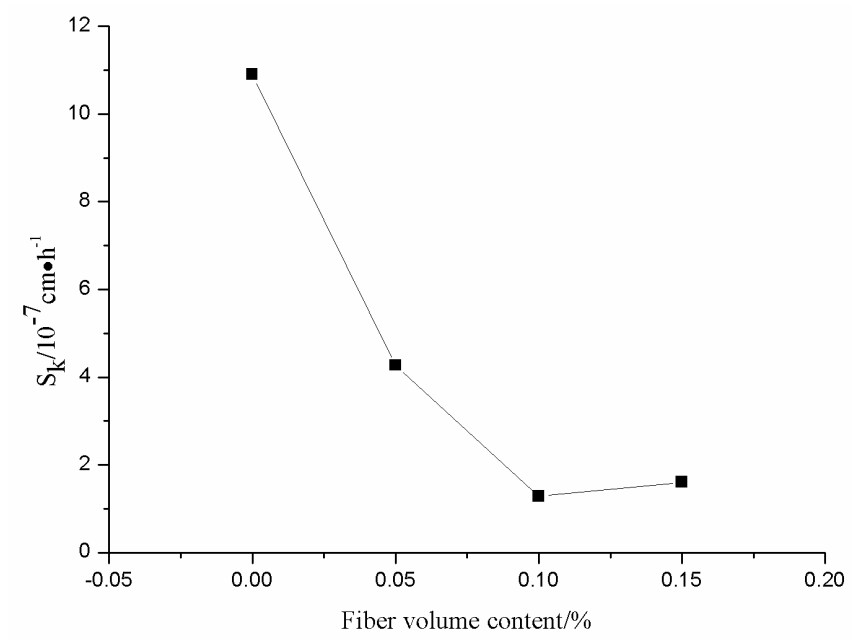

Fig. (5). Plot of relative water penetration coefficient of hardened SCC with fibrillated polypropylene fiber $v s$. fiber volume content.

\subsubsection{The Charge Passed}

The test results from the charge passed experiment of the hardened SCC reinforced with fibrillated polypropylene fiber are shown in Fig. (7) indicating constant $(12 \mathrm{~mm})$ fiber length. With the increase in fiber volume content, the charge passed of the hardened SCC reinforced with fibrillated polypropylene fiber slowly increased firstly, and then sharply increased at the turning point of volume content at $0.10 \%$; with the increase of curing period, the charge passed 


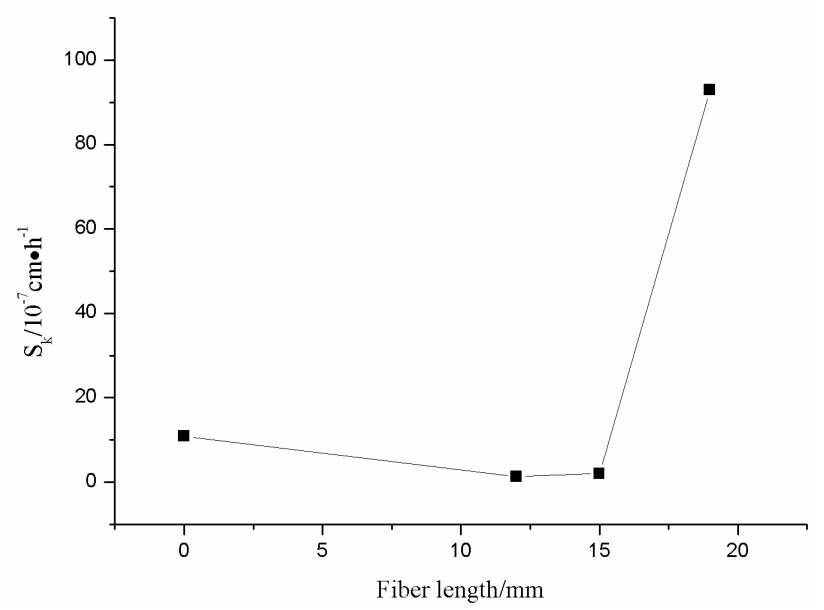

Fig. (6). Plot of relative water penetration coefficient of hardened SCC with fibrillated polypropylene fiber $v s$. fiber length.

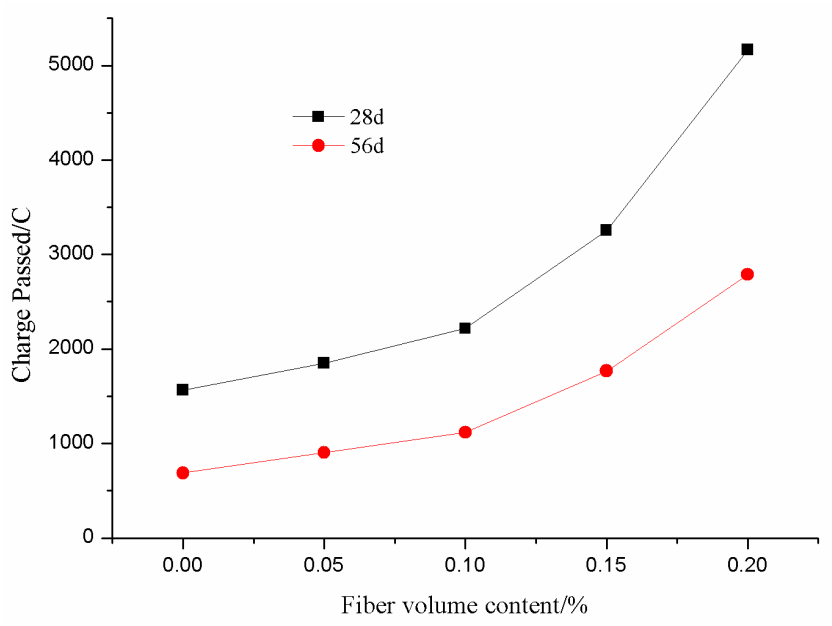

Fig. (7). Plot of charge passed of hardened SCC with fibrillated polypropylene fiber $v s$. fiber volume content.

of the hardened SCC reinforced with fibrillated polypropylene fiber decreased, and charge passed of the hardened SCC reinforced with fibrillated polypropylene fiber with the volume content of $0.10 \%$ in 56-day curing period was $1120 \mathrm{C}$, and the permeability of chloride ion was low (in accordance with JTJ/T 193-2009[24] and ASTM C 1202 [26]; the charge passed should be between 1000C and 2000 C), which meets the requirements of the first class of service life (100 years) (the charge passed should be less than 1500 C) in Code for Durability Design of Railway Concrete Structure (TB10005-2010) [27]. It is shown in Fig. (8) that when the fiber volume content is constant $(0.10 \%)$, with the increase in fiber length, the charge passed slowly increases firstly and then dramatically increases at the turning point of $15 \mathrm{~mm}$; the charge passed of different hardened SCC reinforced with fibrillated polypropylene fiber also decreases with the increase of the curing period. Therefore, it is unfavorable for the fiber volume content to exceed $0.10 \%$, and the fiber length to exceed $15 \mathrm{~mm}$.

The differences in results of water penetration and chloride ion penetration tests of the hardened concrete reinforced with fiber can be interpreted with reference to Wang Ke-jin and other scholars' opinions on the distribution characteristics of pores in fiber reinforced concrete[28]; compared with ordinary concrete, the addition of fiber leads to the increase of total porosity of concrete and the diameter of the most probable pore, as well as the possible increase of charge passed, which has been proven by the mercury injection test. Moreover, the cracking resistance of fibrillated polypropylene fibers reduces early-age shrinkage, so the harmful pores (whose diameter is above 100nm) decline and the harmless pores (whose diameter is less than 100nm) increase, which has also been proven. Compared with the water penetration test, the method of charge passed can better reflect the changes in porous structures. Therefore, the enhancement effect of fiber on the impermeability of the hardened SCC should be comprehensively evaluated based on the water permeability and chloride ion permeability of the hardened SCC reinforced with fibrillated polypropylene fiber.

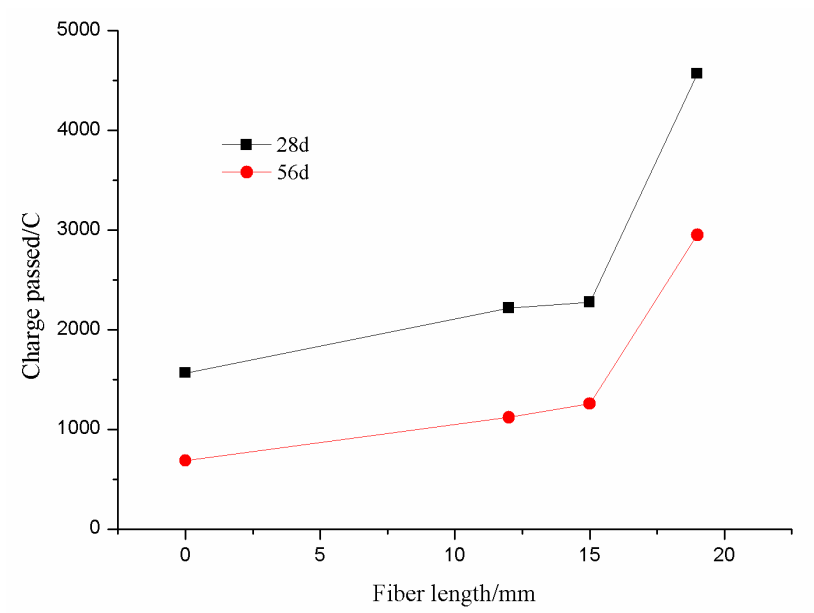

Fig. (8). Plot of charge passed of hardened SCC with fibrillated polypropylene fiber $v s$. fiber length.

\section{ANALYSES ON IMPERMEABILITY PROPERTIES}

The hardened SCC reinforced with fibrillated poly propylene fiber possesses low water-binder ratio and good water impermeability, thus the influence of fiber on the permeability of the hardened SCC cannot be quantitatively evaluated by the impermeability gradation test.

With the increase in fiber volume content, the modified relative water penetration coefficient firstly decreases, and then dramatically increases (when fiber length is constant). When the volume content of fibrillated polypropylene fiber is no more than $0.10 \%$, the fiber is well dispersed and has large specific surface area. A large number of disordered distributed fibrillated polypropylene fibers adsorb a large amount of water, reducing bleeding channels, and are also inter-extended and overlapped with $\mathrm{C}-\mathrm{H}-\mathrm{S}$ gel to form a network structure shown in Fig. (9), which ensures good adhesion between fiber and matrix and improves the porous structure. At the same time, the cracking resistance and enhancement $[3,8,10,12,17,18,28-30]$ of fiber prevent the occurrence and development of micro-cracks, by which the porous structure is further improved. Therefore, the water impermeability of the hardened SCC reinforced with fibrillated polypropylene fiber is enhanced. However, when the volume content of fibrillated polypropylene fibers reaches $0.15 \%$, a poor dispersion is shown under the electronic microscope displayed in Fig. (10) and the initial defects increase, and water permeability also begins to 
increase. Of course, the results can be random and be only used as a qualitative interpretation of the SEM test. For further researches, lots of SEM tests are required to be carried out for the statistical analysis.

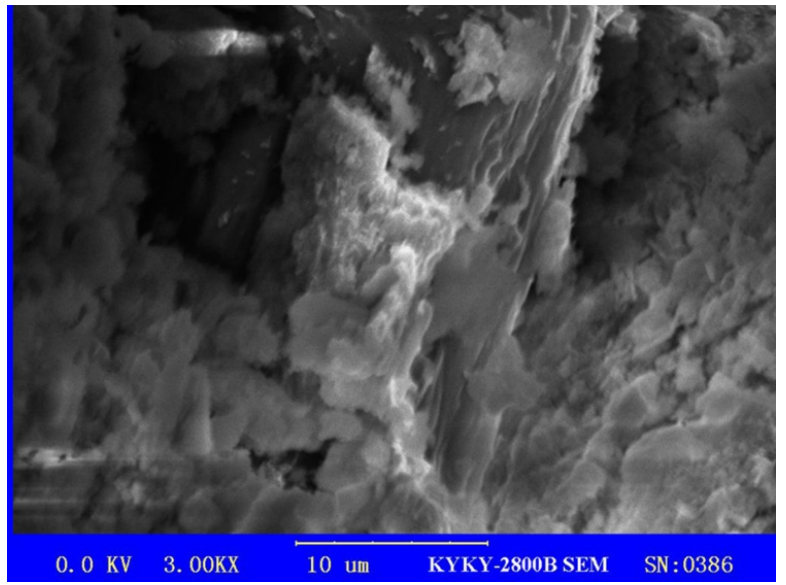

Fig. (9). Microstructure of SCC with $0.10 \%$ fibrillated polypropylene fiber under SEM

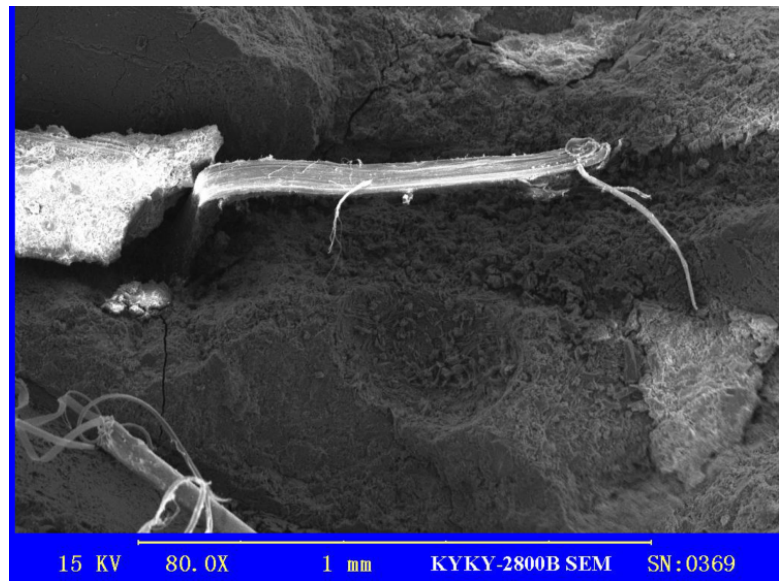

Fig. (10). Microstructure of SCC with $0.15 \%$ fibrillated polypropylene fiber under SEM

With the increase in fiber volume content (fiber length is constant), charge passed slowly increases firstly, and then sharply increases, while the modified relative water penetration coefficient firstly decreases and then increases. With the increase in fiber length (volume content is constant), the modified relative water penetration coefficient decreases firstly and then increases sharply, while the charge passed is of little variation firstly and then sharply increases. The law that water permeability and chloride ion permeability change with the fiber volume content seems to be controversial, but it can be analyzed from the aspects of the material porosity distribution. The increase of Coulomb value (it should be noted that the results of charge passed belong to the lower gradation of the penetration of chloride ions) is due to the fact that the addition of fiber leads to the increase in the total porosity and the diameter of the most probable pore. Taking the fiber content of $0.10 \%$ for example, the total porosity increases by $51 \%$. However, although the total porosity and the diameter of the most probable pores increase (the studies of fiber concrete and mercury injection test have also confirmed ), due to the cracking resistance and enhancement of fiber, the amount of big pores and transitional pores decline, thus the microstructure is also improved. That is to say, the harmless pores (whose diameter is less than 100nm) increase and the harmful pores (whose diameter is more than $100 \mathrm{~nm}$ ) decrease. As a result, the water permeability is improved (taking the fiber content of $0.10 \%$ at the fiber length of $12 \mathrm{~mm}$ for example, the diameter distribution harmful pores reduced from $40 \%$ in referenced hardened SCC to $20 \%$ ). Next, the author will conduct a systematical study on the characteristics of pore diameter distribution and will further analyze the above phenomenon.

\section{CONCLUSION}

Through the above research, the following conclusions can be drawn:

1) With the increase of fiber volume content, the tensile strength (including the splitting strength and flexuraltensile strength) at first increases and then decreases. The total porosity increases with the fiber volume content, while the harmful pore volume content firstly decreases and then increases. Based on the strength, the maximum fiber volume content is $0.15 \%$ with proper fiber length. At this time, the 28-day flexural strength and splitting strength of the hardened SCC are respectively raised by $32 \%$ and $29 \%$ compared with the referenced hardened SCC. When the fiber volume content is constant $(0.10 \%)$, the splitting strength and flexural tensile strength of the hardened SCC reinforced with fibrillated polypropylene fiber increase with the increase in fiber length, but the increment is not so significant (the maximum growth is only $6 \%$ ), and the total porosity and the harmful porosity increase with the increase in fiber length.

2) The impermeability gradation is not suitable for quantitative evaluation of the hardened SCC reinforced with fibrillated polypropylene fiber. It is advisable to employ the modified relative water penetration coefficient and the charge passed of chloride ion to comprehensively evaluate its impermeability properties. When the fiber length of fibrillated polypropylene fibers is constant, with the increase in fiber volume content, the modified relative water penetration coefficient of the hardened SCC firstly decreases and then increases with the maximum volume content of $0.10 \%$; when the fiber volume content is constant, with the increase in fiber length, the modified relative water penetration coefficient firstly decreases, and then increases sharply. It is unfavorable for the fiber length to exceed $15 \mathrm{~mm}$. With the increase in fiber volume content, the permeability of chloride ion of the hardened SCC reinforced with fibrillated polypropylene fiber increases smoothly at first, and then dramatically increases. It is unfavorable for the volume content to exceed $0.10 \%$ and fiber length to exceed $15 \mathrm{~mm}$.

3) Comprehensively taking the workability, strength and impermeability into consideration, when the volume content of fibrillated polypropylene fibers is $0.10 \%$ and the fiber length is between 12 and $15 \mathrm{~mm}$, compared with the referenced hardened SCC, the 28-day flexural-tensile 
strength and 28-day splitting strength of the hardened SCC reinforced with fibrillated polypropylene fiber (fiber volume content of $0.10 \%$ and fiber length of $12 \mathrm{~mm}$ ) are respectively raised by $26 \%$ and $24 \%$. Its water impermeability gradation is greater than $\mathrm{P} 12$, the modified relative water penetration coefficient is reduced by $88 \%$, and the 56-day Coulomb value is $1120 \mathrm{C}$.

\section{CONFLICT OF INTEREST}

The authors confirm that this article content has no conflict of interest.

\section{ACKNOWLEDGEMENTS}

This project is supported by the National Key Basic Research Development Plan (973) Project (2012CB723305), National Natural Science Foundation of China (Grant No. 51478071), the Application Foundation Research Project of Ministry of transport (Grant No. 2013319814180), the Chongqing Foundation and Frontier Research Plan Project (cstc2013jcyjA 30011) and National \& Local Joint Engineering Laboratory of Traffic Civil Engineering Materials in Chongqing Jiaotong University (LHSYS-2012002).

\section{REFERENCES}

D. Bonen, and S. P. Shah, "Fresh and hardened properties of selfconsolidating concrete", Progress in Structural Engineering and Materials, vol. 7, no. 1, pp. 14-26, 2005.

[2] M. C. Brown, C. Ozyildirim, and W. L. Duke, "Investigation of fiber-reinforced self-consolidating concrete", Report, Federal Highway Administration, Virginia, 2010. [Online] Available from http://www.virginiadot.org/vtrc/main/online_reports/pdf/10-r8.pdf [Accessed Aug. 19, 2013].

[3] X. B. He, and B. Yan, "Strength properties and permeability of polypropylene monofilament fiber reinforced self-compacting concrete", Journal of Civil, Architectural and Environmental Engineering, vol. 35, no. 3, pp. 137-144, 2013.

[4] S. P. Shah, R. P. Ferron, N. A. Tregger, L. Ferrara, and M. W. Beacraft, "Self-consolidating concrete: now and future", In: Proceedings of 65 of RILEM on Design, Performance and Use of Self-Consolidating Concrete, Beijing, China, pp. 3-15, 2009.

[5] H. Mazaheripour, S. Ghanbarpour, S. H. Mirmoradi, and I. Hosseinpour, "The effect of polypropylene fibers on the properties of fresh and hardened lightweight self-compacting concrete", Construction and Building Materials, vol. 25, no. 1, pp. 351-358, 2011.

[6] A. S. El-Dieb, and M. M. R. Taha, "Flow characteristics and acceptance criteria of fiber-reinforced self-compacted concrete (FR-SCC)", Construction and Building Materials, vol. 27, no. 1, pp. 585-596, 2012.

[7] S. G. Liu, and Y. N. Ding, "Study on early age restrained shrinkage of fiber reinforced self-compacting concrete", Journal of Building Materials, vol. 11, no. 1, pp. 8-13, 2008.

[8] X. B. He, and Y. Cao, "Mechanical properties of self-compacting concrete reinforced with fibrillated polypropylene fiber and their relationship", Journal of Basic Science and Engineering, vol. 22, no. 3, pp. 501-511, 2014.

[9] O. Gencel, C. Ozel, W. Brostow, G. Martínez-Barrera, "Mechanical properties of self-compacting concrete reinforced with polypropylene fibers", Materials Research Innovations, vol.15, no. 3, pp. 216-225, 2011.
[10] B. Felekoglu, K. Tosun, and B. Baradan, "Effects of fibre type and matrix structure on the mechanical performance of self-compacting micro-concrete composites", Cement and Concrete Research, vol. 39, no. 11, pp. 1023-1032, 2009.

[11] S. R. Luo, and H. Li, "Experimental investigation on the fracture energy of fiber reinforced self-compacting concrete", Engineering Mechanics, vol. 27, no. 12, pp. 119-123, 2010.

[12] X. B. He, and Q. Shen, "Early strength and fracture properties of polypropylene fiber reinforced self-consolidating concrete", Journal of Huazhong University of Science and Technology (Natural Science Edition), vol. 41, no. 3, pp. 115-121, 2013.

[13] X. B. He, and Q. G. Yang, "Research on impact properties of flexible fiber reinforced self-compacting concrete in middle-low intensity", In: Proceedings of 65 of RILEM on Design, Performance and Use of Self-Consolidating Concrete, Beijing, China, pp. 577-585, 2009.

[14] M. Uysal, and H. Tanyildizi, "Estimation of compressive strength of self-compacting concrete containing polypropylene fiber and mineral additives exposed to high temperature using artificial neural network", Construction and Building Materials, vol. 27, no. 1, pp. 404-414, 2012.

[15] K. K. Sideris, and P. Manita, "Residual mechanical characteristics and spalling resistance of fiber reinforced self-compacting concretes exposed to elevated temperatures", Construction and Building Materials, vol. 41, pp. 296-302, 2013.

[16] B. Persson, "On the internal frost resistance of self-compacting concrete, with and without polypropylene fibres", Materials and Structures, vol. 39, no. 291, pp. 707-716, 2006.

[17] E. Ozbay, M. Lachemi, F. Cassagnebere. "Effects of fiber type on the properties of fibre-reinforced self-compacting concretes", In: Proceedings, Annual Conference of Canadian Society for Civil Engineering, Ottawa, Canada, pp. 1646-1653, 2011.

[18] D. J. Hannant, "Durability of polypropylene fibers in Portland cement-based composites: Eighteen years of data", Cement and Concrete Research, vol. 28, no. 12, pp. 1809-1817, 1998.

[19] I. Hager, and T. Tracz, "The impact of the amount and length of fibrillated polypropylene fibres on the properties of HPC exposed to high temperature", Archives of Civil Engineering, vol. 56, no. 1, pp. 57-68, 2010.

[20] X. B. He, B. Yan, J. Y. Gu, and Q. Shen, "Combined impacts of polypropylene fibres on workability, strength and permeability of SCC", Magazine of Concrete Research, vol. 66, no. 31, pp. 127$140,2014$.

[21] JGJ/T 221-2010, "Technical Specification for Application of Fiber Reinforced Concrete", Guangming Daily Press, Beijing, China, 2010.

[22] JTG E30-2005, Test Method of Cement and Concrete for Highways, China Communications Press, Beijing, China, 2005.

[23] GB 50164-2011, Standard for Quality Control of Concrete, Guangming Daily Press, Beijing, China, 2011.

[24] JGJ/T 193-2009, Standard for Inspection and Assessment of Concrete Durability, China Architecture and Building Press, Beijing, China 2009.

[25] SL 352-2006, Test Code for Hydraulic Concrete, China Waterpower Press, Beijing, China, 2006.

[26] ASTM C1202 - 12, "Standard Test Method for Electrical Indication of Concrete's Ability to Resist Chloride Ion Penetration", ASTM Press, USA, 1997.

[27] TB 10005-2010, Code for Durability Design of Railway Concrete Structure, China Railway Publishing House, Beijing, China, 2010.

[28] K. J. Wang, S. P. Shah, and P. Phuaksuk, "Plastic Shrinkage cracking in concrete materials-Influence of fly ash and fibers", Materials Journal, vol. 98, no. 6, pp. 458-464, 2011.

[29] X. B. He, Q. G. Yang, and G. J. He, "Anti-erosion property of polypropylene fiber reinforced cement-stabilized macadam base material", Journal of Building Material, vol. 13, no. 2, pp. 263267, 2010.

[30] X. B. He, F. Huang, and C. Y. Zhang, "Mechanism and experimental verification of degradation of rc beams induced by concrete/rebar bonding failure", Key Engineering Materials, vol. 452/453, pp. 877-880, 2011. 